\title{
Diversidad de micorrizas arbusculares en pasto colosuana (Bothriochloa pertusa (L) A. Camus de fincas ganaderas del municipio de Corozal-Sucre
}

\author{
Diversity of arbuscular mycorrhizae in grass colosuana \\ (Bothriochloa pertusa (L) A. Camus of livestock farms of the \\ municipality of Corozal- Sucre
}

\author{
Alexander Pérez C, ${ }^{1 *}$ Ph.D, Catalina Botero $L^{2}{ }^{2}$ M.Sc, Maria Cepero G, ${ }^{3}$ M.Sc.
}

\begin{abstract}
${ }^{1}$ Universidad de Sucre, Facultad de Ciencias Agropecuarias, Grupo de investigación Bioprospección Agropecuaria. ${ }^{2}$ Investigadora. ${ }^{3}$ Universidad de los Andes, Facultad de Educación, departamento de Biología Colombia. *Correspondencia: alexpcor@yahoo.com
\end{abstract}

Recibido: Septiembre de 2010; Aceptado: Agosto de 2011.

\begin{abstract}
RESUMEN
Objetivo. Caracterizar comunidades de hongos formadores de micorrizas arbusculares (HMA) en rizosfera del pasto Colosuana (Bothriochloa pertusa (L). A. Camus) en fincas ganaderas del municipio de Corozal, departamento de Sucre. Materiales y métodos. Se muestrearon 43 fincas ganaderas distribuidas en 4 zonas agroecológicas del municipio. Se realizó aislamiento de esporas del suelo, determinación del porcentaje de colonización en raíces, separación e identificación de morfotipos de HMA. Resultados. El ANOVA multifactorial mostró que el número de esporas de HMA y el porcentaje de colonización en raíces de Colosuana (Bothriochloa pertusa), fueron mayores en las fincas localizadas en la zona agroecológica 4 y 2, respectivamente. 31 morfotipos de HMA fueron aislados, un $96.9 \%$ correspondieron a morfotipos con características similares a especie dentro del género Glomus y $3.1 \%$ a Gigaspora. Conclusiones. La alta diversidad de morfotipos de HMA asociados a Colosuana se convierte en un recurso biológico alternativo, cuyo manejo, conservación y efectos sobre la productividad, genera beneficios ambientales al mejorar las condiciones físico-químicas y biológicas del suelo. Se propone su inclusión en el inventario de la diversidad de microorganismos en estos agroecosistemas.
\end{abstract}

Palabras clave: Bothriochloa pertusa, diversidad, fincas, micorrizas (Fuente:CAB).

\section{ABSTRACT}

Objective. Characterize communities of fungi that produce arbuscular mycorrhizal (AMF) in the rhizosphere of the Colosuana grass (Bothriochloa pertusa (L). A. Camus) in cattle farms located in the municipality of Corozal, Sucre. Materials and methods. 43 cattle farms were sampled in 4 agroecological zones of the municipality. Spore isolation from the ground was performed, determining the percentage of root colonization, separation and identification of morphotypes of AMF. Results. The multifactor ANOVA showed that the number of AMF spores and the percentage of root colonization of Colosuana (Bothriochloa pertusa) was higher on farms located in the agro-ecological zone 4 and 2, respectively. 31 AMF morphotypes were isolated; a $96.9 \%$ corresponded to morphotypes with 
characteristics similar to species within the genus Glomus and $3.1 \%$ to Gigaspora. Conclusions. The high diversity of morphotypes of AMF associated Colosuana become an alternative biological resource, and its management, conservation and effects on productivity, generate environmental benefits by improving the physic-chemical and biological conditions of the soil. Its inclusion in the inventory of the diversity of microorganisms in these agro ecosystems is proposed.

Key words: Bothriochloa pertusa, diversity, farm, mycorrhizal (Source:CAB).

\section{INTRODUCCIÓN}

La rizosfera es un hábitat heterogéneo, continuo y natural en donde ocurren diferentes tipos de interacciones entre los microbios del suelo y las plantas. Las interacciones benéficas entre microbios-planta en la rizosfera son los principales determinantes de la salud de plantas y la fertilidad del suelo. Los hongos formadores de micorrizas arbusculares (HMA) son uno de los simbiontes microbianos más importantes para la mayoría de las plantas. En condiciones limitadas de fosfato, los hongos AM, pueden influir en el desarrollo de la comunidad de plantas, la absorción de nutrientes, las relaciones y la productividad del suelo. También pueden actuar como bioprotectantes contra agentes patógenos y en condiciones de estrés tóxicos (1).

En la rizosferas los HMA interactúan con diversos grupos de bacterias. Esta interacción son establecidas durante todas la etapas del ciclo de vida de las micorrizas, desde la formación de esporas, germinación, colonización dentro de las raíces de las planta hasta la emisión de las hifas externas (2). Los estudios taxonómicos de HMA, tradicionalmente fueron basados en la morfología y apariencia de las esporas. Numerosas familias y géneros han sido distinguidos fundamentalmente por la unión de la hifa y el modo de formación de la espora, mientras que la subestructura de las paredes de las esporas jugó un papel importante en la identificación de las especies. Desde principios de la década pasada, los HMA han sido objeto de investigaciones basadas en estudios moleculares mediante la extracción del $A D N$, para comprender aspectos concernientes a la filogenia y taxonomía de estos organismos como su identificación y monitoreo en diversos agroecosistemas (3).

La clasificación de los hongos formadores de micorrizas fueron ubicados en la división Zygomycota, orden Glomales, por poseer hifas cenocíticas característica de la división. Sin embargo las micorrizas son diferentes del linaje de este linaje, debido a características tales como la formación de asociación mutualista y la no de formación de zigospora. Los análisis del rADN exponen una clara separación de las micorrizas arbusculares del resto de grupos de hongos, ubicándolas y separándolas en un nuevo phyllum, Glomeromycota $(4,5)$. El orden Glomeromycota comprende 4 órdenes, 8 familias, y 10 géneros (6). Recientemente dos nuevos géneros de micorrizas arbusculares han sido descritos Klukospora y Intraespora (7).

Las pasturas del Caribe colombiano están constituidas por gramíneas de alto potencial productivo como guinea (Panicum máximum), angleton (Dichanthium aristatum), puntero (Hyparrhenia rufa) y pará (Brachiaria mutica), algunas especies naturalizadas como Colosuana o kikuyina (Bothriochloa pertusa), convirtiéndose en fuente exclusiva de alimentación animal. El pasto colosuana, alcanza un total de $274.005 \mathrm{Ha}$, distribuidas en 19 municipios del departamento de Sucre (8); siendo el municipio de Corozal el de mayor área sembrada con esta especie de pasto en la región de 32.223 ha (9).

Hoy se considera que la sostenibilidad, tanto de ecosistemas naturales como de agroecosistemas, depende principalmente del equilibrio entre los componentes biológicos del suelo; de hecho se acepta que la tendencia actual de investigación en microbiología es el estudio de los microorganismos desde punto de vista de diversidad, ecológico, genético, bioquímico y fisiológico con relación a la nutrición y protección de las plantas (10). Teniendo en cuenta la necesidad de conocimiento sobre presencia y diversidad de microorganismos asociadas a agroecosistemas de pastura en condiciones específicas de la costa Caribe colombiana, se planteó el presente trabajo cuyo objetivo fue aislar e identificar hongos formadores de micorrizas asociadas a pasto colosuana (Bothriochloa pertusa (L) A. Camus) en fincas ganaderas localizadas en el municipio de Corozal, departamento de Sucre, Colombia.

\section{MATERIALES Y MÉTODOS}

Sitio de estudio. Se tomaron 43 fincas ganaderas del municipio de Corozal (Sucre) con pastura predominante de Bothriochloa pertusa ( $L$ ) A, distribuidas en cuatro zonas agrológicas 
según la clasificación de tierras por su capacidad de uso y manejo (11): zona 1 (III sc - IV hs), zona 2 (VII sc - IV esc), zona 3 (VI sc - VI esc) y zona 4 (VII sc - VII esc).

Zona 1. Los suelos ocupan áreas de relieve plano a ligeramente inclinados con pendientes que oscilan $1-3 \%$ y $3-4 \%$, moderadamente profundos, bien a imperfectamente drenados, de texturas moderadas a finas, permeabilidad moderada a lenta, retención de humedad media a lenta, $\mathrm{pH}$ moderadamente ácida a neutra, alta disponibilidad de $\mathrm{Ca}, \mathrm{Mg}$ y $\mathrm{K}$, bajos contenidos de fósforo disponible, contenidos de materia orgánica bajos a medios y fertilidad baja a moderada.

Las limitaciones de la subclase III sc radica en: la profundidad efectiva a modera limitada por horizontes arcillosos compactados, permeabilidad baja, poca capacidad de aireación, contenidos bajos de materia orgánica y fósforo disponible y falta de humedad. Actualmente se encuentran pastos naturales, maíz, yuca y asocio yuca / ñame establecidos en esta subclase.

Los suelos de la subclase IV hs está integrado por suelos pobremente drenados, superficiales a muy superficiales, arcillosos, poco permeables, de alta retención de humedad, pegajosos, plásticos, pH moderada a fuertemente ácida, mediano a altos contenidos de cationes intercambiables, porcentajes de fósforos disponibles y materia orgánica bajos, fertilidad actual moderada. En condiciones actuales son aptos para arroz y pastos naturales resistentes al exceso de humedad.

Zona 2. A la subclase VII sc pertenecen suelos fuertemente ondulados, con pendientes de 12 - 25\%, presentan erosión ligera, suelos bien drenados, moderadamente profundos, de texturas moderadas a finas, mediana retención de humedad, permeabilidad moderada. Químicamente son suelos de reacción ácida a neutra y fertilidad moderada. Las principales limitaciones son las pendientes fuertemente onduladas, el bajo contenido de nitrógeno, fósforo y materia orgánica. Una parte de esta área está ocupada por ganadería extensiva en pastos naturales y rastrojo.

Los suelos de la subclase IV esc están localizados en áreas de relieve ondulado a fuertemente ondulado, con pendientes de $12-25 \%$ y algunos sectores con $1-12 \%$. Son profundos a moderadamente profundos, en su mayoría arcillosos, con inclusiones de texturas moderadamente finas, bien drenados, de media a alta retención de humedad, sufre agrietamiento durante la época seca. Las características químicas indican que tiene reacción ácida a ligeramente alcalina, altos contenidos de calcio, magnesio y potasio, contenidos de materia orgánica y fósforo disponibles bajos. El uso actual es la ganadería extensiva en pastos naturales; en algunos sectores se encuentran cultivos de algodón, maíz, sorgo y yuca.

Zona 3. La subclase VI sc contienen suelos con pendientes de $12-25 \%$ y $25-50 \%$; los suelos son superficiales a moderadamente profundos, de textura franca gruesa a arcillosa, bien a excesivamente drenados. Tienen susceptibilidad a la erosión, buena permeabilidad, mediana a baja retención de humedad, reacción neutra a ligeramente ácida y fertilidad moderada. Las limitaciones para el manejo y uso de estos suelos son la poca disponibilidad de agua, poca profundidad efectiva, contenidos de fósforo disponible, nitrógeno y materia orgánica bajos. El uso actual de estas tierras es la ganadería extensiva con pastos naturales, además se encuentran cultivos como maíz, yuca, ñame y algunos frutales.

En la subclase VI esc se agrupan suelos con pendientes de $12-25 \%$ y $25-50 \%$, presentan suelos con características morfológicas, físicas y químicas muy variadas, la profundidad efectiva varía de superficial a moderada. Presentan textura franco gruesa a franco fina o arcillosa, fertilidad baja a moderada y reacción ácida a neutra. Las limitaciones de la anterior subclase es de índole química, deficiencia de fósforo y macronutrientes y altos contenidos de aluminio; limitando su aptitud a la preservación de la cobertura vegetal. El mantenimiento de pastos naturales exige severas precauciones (sobre pastoreo) a fin de evitar el progreso de la erosión.

Zona 4. En la subclase VII sc están presentes suelos con pendientes de hasta $12-25 \%$, ligeramente erosionados. Los suelos están limitados por capas de gravas muy superficiales, tienen reacción fuertemente ácida, saturación de bases, fósforo y materia orgánica bajos. La actitud para cultivos es baja, debido a la poca profundidad efectiva y a la escasa fertilidad. El mejor uso que se le da actualmente son los pastos. El uso actual es la ganadería extensiva y pequeños cultivos de subsistencia.

En la subclase VII esc se encuentran suelos con pendientes $1-12 ; 12-25 ; 25-50$ y $50-75 \%$, con erosión moderada a severa. Los suelos son superficiales a profundos, bien drenados, de baja estabilidad estructural, permeabilidad 
moderada, retención de humedad de baja a media, reacción ligeramente ácida a neutra y fertilidad moderada a baja. Presentan limitaciones severas por pendientes fuertemente inclinadas, susceptibles a la erosión y en algunos casos a la baja fertilidad.

Un tubo PVC de $3.8 \mathrm{~cm}$ de diámetro y $25 \mathrm{~cm}$ de longitud, fue usado para tomar las muestras a una profundidad entre $0-20 \mathrm{~cm}$, introduciendo, rotando y extrayendo el cilindro con la muestra (suelo y raíces). En cada finca se tomaron entre 15-20 muestras, estas se homogenizaron por finca para conformar una con un peso de 2000 gramos. Estas muestras fueron empleadas para el aislamiento de esporas, determinación del porcentaje de colonización en raíces e identificación de morfotipos.

Análisis microbiológico. Las muestras etiquetadas en bolsas plásticas fueron llevadas al laboratorio y se conservaron a $4^{\circ} \mathrm{C}$ hasta su posterior análisis. Para el aislamiento de esporas, las muestras colectadas en campo fueron tamizadas para separar las partes gruesas de suelos (piedras, cascajos) y raíces. Seguidamente, se procedió al aislamiento de esporas de HMA, (12). El conteo fue realizado en cámara cuenta nematodos (Advance Equine Products 5004-228th Avenue SI Issaquah, Washington 98029 USA). La densidad de esporas fue estimada por triplicado y se expresó en términos de número total de esporas $/ 100 \mathrm{~g}$ de suelos por finca y por zona agroecológica.

El contenido de cada cámara fue colocado en cajas de Petri, observada al estereoscopio y con la ayuda de una aguja de disección se agruparon morfotipos, teniendo en cuenta similitud de forma, color y tamaño de las esporas. Con la ayuda de una micropipeta se extrajeron las esporas de los diferentes morfotipos encontrados, se colocaron en tubos de ensayos con agua estéril, se rotularon con el número de la finca donde fueron aislados y se conservaron en nevera a $4^{\circ} \mathrm{C}$ durante 3 días para su posterior identificación. Los morfotipos aislados fueron depositaron en cajas de Petri, se observaron al estereoscopio para detallar sus características en agua, verificar y eliminar esporas de otros morfotipos y partículas contaminantes. Una vez limpias las esporas y verificado los morfotipos, se realizó la identificaron a nivel de géneros, mediante técnicas internacionalmente reconocidas (13).

El porcentaje de colonización de HMA en raíces de Bothriochloa pertusa (L) A, fue determinado mediante técnica de coloración de raíces. Las raíces coloreadas fueron colocadas sobre láminas cubiertas con laminillas, para su observaron con objetivo 40X. Para estimar el porcentaje de colonización en raíces se contaron 100 campos ordenadamente por muestra. En cada muestra se observó la presencia de campos negativos (sin presencia de estructuras colonizantes) y positivos (con presencia de estructuras colonizantes). En los campos positivos se tuvo en cuenta el tipo de estructuras (arbusculos, vesículas, hifas y esporas) presentes dentro de cada raíz. Los resultados obtenidos de los campos positivos fueron expresados en términos de porcentaje (14).

Análisis estadístico. La relación entre las variables densidad poblacional (número de espora/100 g de suelo) y colonización (\%) en función de zonas agroecológicas y fincas, se realizó mediante ANOVA multifactorial (15). Se Realizaron varias pruebas y gráficas para determinar qué factores tuvieron un efecto estadísticamente significativo sobre las variables. Se evaluó la significancia de las interacciones entre los factores, las cuales fueron evidenciadas de acuerdo con los resultados de las pruebas $-f$ obtenida mediante ANOVA lo que permitió identificar los factores de mayor significancia. Los datos numéricos fueron analizados en el programa estadístico R (16).

\section{RESULTADOS}

Los resultados del ANOVA multifuncional entre la variable número de esporas $/ 100 \mathrm{~g}$ de suelo, con relación a zonas agroecológicas y fincas ganaderas mostró diferencias altamente significativas ( $p$ value $=0.0000$ ) para los componentes zonas y fincas (Tabla 1). Para visualizar los resultados de significancia obtenidos en la tabla 1 , se realizaron gráficos de boxplot. En la figura 1, se observa, que el mayor número de esporas de HMA fueron encontradas en las fincas pertenecientes a la zona agroecológica $4(4200 \pm 6000)$, seguida de la zona $2(2200 \pm 4000)$ en contraposición a la zona 3 que mostró las menores densidades

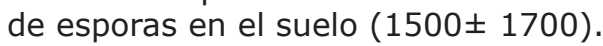

Tabla 1. Resultados del ANOVA multifactorial para número de esporas/100 g de suelo en función de zonas agroecológicas y fincas ganaderas.

\begin{tabular}{lccccc}
\hline \multicolumn{1}{c}{ Fuente } & $\begin{array}{c}\text { Suma de } \\
\text { Cuadrados }\end{array}$ & GI & $\begin{array}{c}\text { Cuadrado } \\
\text { Medio }\end{array}$ & $\begin{array}{c}\text { Razón } \\
\mathbf{F}\end{array}$ & $\begin{array}{c}\text { Valor } \\
\mathbf{P}\end{array}$ \\
\hline Efectos principales & & & & & \\
A: Fincas & $9.59697 \mathrm{E} 7$ & 15 & $6.39798 \mathrm{E} 6$ & 7.62 & $0.00 * * *$ \\
B: Zona agroecológica & $3.13203 \mathrm{E} 8$ & 3 & $1.04401 \mathrm{E} 8$ & 124.29 & $0.00 * * *$ \\
Residuos & $9.23962 \mathrm{E7}$ & 110 & 839965 & & \\
Total & $5.04165 \mathrm{E} 8$ & 128 & & & \\
\hline$* * *:$ Altamente significativo al 95.0\% de nivel de confianza. &
\end{tabular}




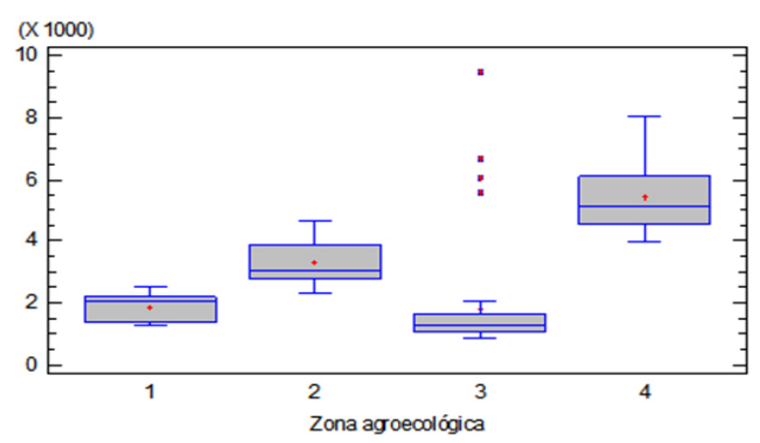

Figura 1. Resultado de grafico de Boxplot de densidad de esporas $/ 100 \mathrm{~g}$ de suelo de HMA y zonas agroecológica. 1: zona 1,2 : zona 2, 3: zona 3 y 4: zona 4.

El ANOVA multifuncional para porcentaje de colonización de HMA en raíces del pasto colosuana, en función a zonas agroecológicas y fincas ganaderas mostró diferencias altamente significativas para el componente zonas y diferencia no significativas para fincas (Tabla 2). Los resultados del gráfico de boxplot (Figura 2), señala, que el mayor porcentaje de colonización en raíces con HMA fueron encontradas en las fincas localizadas en zona $1(46 \pm 75 \%)$, seguida de la zona $3(40 \pm 55 \%)$ en relación a la zona 2 que mostró los menores porcentaje

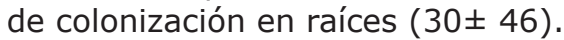

Tabla 2. Resultados del ANOVA multifactorial para número de espora/100 g de suelo en función de zonas agroecológicas y fincas ganaderas.

\begin{tabular}{|c|c|c|c|c|c|}
\hline Fuente & $\begin{array}{c}\text { Suma de } \\
\text { Cuadrados }\end{array}$ & GI & $\begin{array}{c}\text { Cuadrado } \\
\text { Medio }\end{array}$ & $\begin{array}{c}\text { Razón } \\
\text { F }\end{array}$ & $\begin{array}{c}\text { Valor } \\
\mathbf{P}\end{array}$ \\
\hline \multicolumn{6}{|l|}{ Efectos principales } \\
\hline A:Fincas & 1576.34 & 15 & 105.089 & 0.84 & $0.6298^{\mathrm{NS}}$ \\
\hline $\begin{array}{l}\text { B:Zona } \\
\text { agroecológica }\end{array}$ & 1944.75 & 3 & 648.251 & 5.18 & $0.0067 * * *$ \\
\hline Residuos & 3002.91 & 24 & 125.121 & & \\
\hline TOTAL & 6602.19 & 42 & & & \\
\hline
\end{tabular}

***: Altamente significativo al $95.0 \%$ de nivel de confianza, ${ }^{\text {Ns: }}$ no hay diferencias

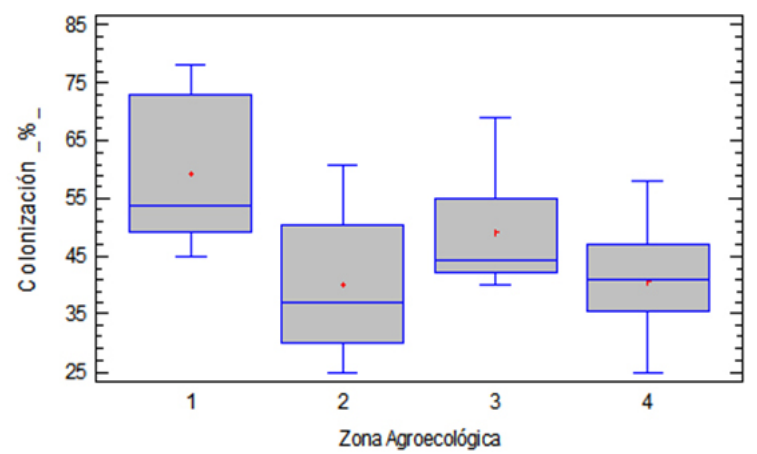

Figura 2. Resultado de grafico de Boxplot colonización (\%) en de HMA y zonas agroecológica. 1: zona 1, 2: zona 2,3 : zona 3 y 4 : zona 4.
Se aislaron 31 morfotipos con características similares (cf) a HMA (Tabla 3, Figuras 3 y 4). Del total de aislamientos, el $96.9 \%$ corresponden a especies del género Glomus y 3.1\% a Gigaspora, reportándose una mayor diversidad en la zona agroecológica 1 con relación a las demás zonas. La mayor diversidad de especies encontradas en este estudio correspondió a los suelos de las fincas localizadas en la zona agroecológica 2. Esta zona, pertenece la subclase VII sc con presencia de suelos fuertemente ondulados, con pendientes de $12-25 \%$, presentan erosión

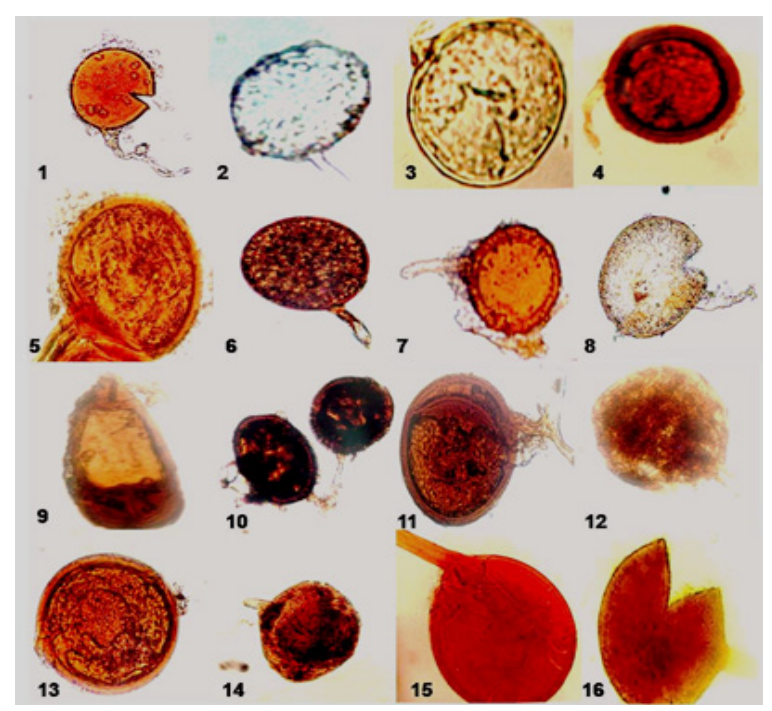

Figura 3. Diversidad poblacional de morfotipos de HMA en rizosfera de pasto colosuana. 1-16: morfotipos de HMA aislados e identificados (Tabla 1).

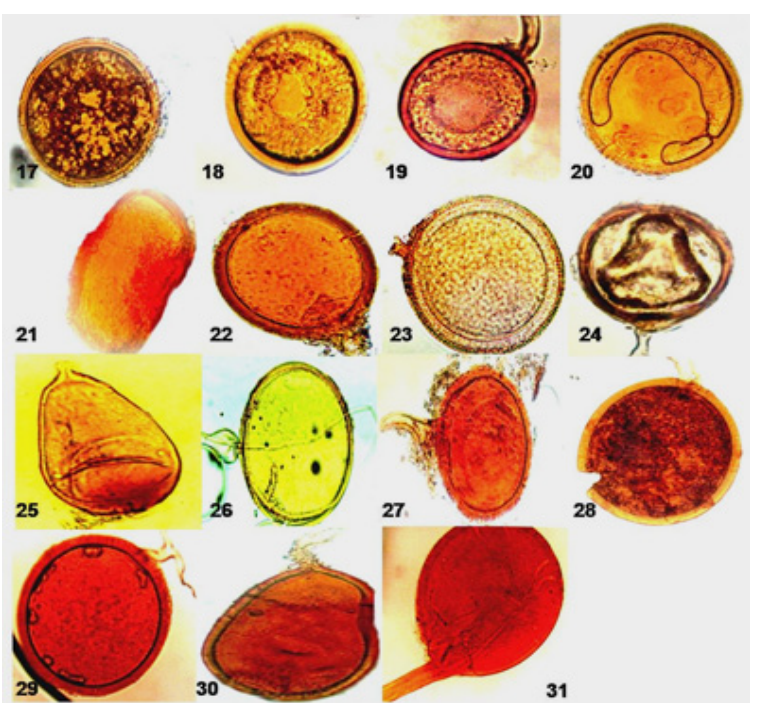

Figura 4. Diversidad poblacional de morfotipos de HMA en rizosfera de pasto colosuana. 1731: morfotipos aislados e identificados (Tabla 1). 
Tabla 3. Riqueza y abundancia de morfotipos de HMA en rizosfera de pasto colosuana

\begin{tabular}{|c|c|c|c|c|c|}
\hline \multirow{2}{*}{\multicolumn{2}{|c|}{ Morfotipos }} & \multicolumn{4}{|c|}{ Zonas agroecológicas } \\
\hline & & $\mathbf{1}$ & 2 & 3 & 4 \\
\hline 1 & Cf Glomus Hoi Berch, S.M. and Trape J.M. 1985. & 1 & 1 & 1 & \\
\hline 2 & Cf Glomus sp & 1 & 0 & 0 & 1 \\
\hline 3 & Cf Glomus segmentatum Trappe, Sponer \& Ivory 1987. & 0 & 0 & 1 & 1 \\
\hline 4 & Cf Glomus citricola Tang \& Zang, 1984. & 1 & 0 & 1 & 0 \\
\hline 5 & Cf Glomus macrocarpum Tulasne \& Tulasne & 1 & 1 & 1 & 0 \\
\hline 6 & Cf Glomus geosporum, (Nicolson \& Gerdermann) Walker, 1982. & 0 & 1 & 1 & 1 \\
\hline 7 & Cf Glomus etunicatum Becker \& Gerdemann, 1977. & 1 & 1 & 1 & 0 \\
\hline 8 & Cf Glomus leptotichum Schenk \& Smith, 1982. & 1 & 0 & 0 & 0 \\
\hline 9 & Cf Glomus taiwanensis (Wu \& Chen, 1987); Morton y Redecker, 2001. & 0 & 1 & 1 & 1 \\
\hline 10 & Cf Glomus ambisporum Smith, \& Schenck, 1986. & 1 & 1 & 0 & 0 \\
\hline 11 & Cf Glomus aggregatum Schenck \& Smith Emende. Korke, 1985. & 1 & 1 & 0 & 1 \\
\hline 12 & Cf Glomus pulvinatum (P. Hennings) Trappe \& Gerdemann, 1975. & 1 & 0 & 0 & 1 \\
\hline 13 & Cf Glomus sp. & 1 & 0 & 0 & 1 \\
\hline 14 & Cf Glomus sp. & 1 & 1 & 0 & 0 \\
\hline 15 & Cf Glomus sp. & 1 & 0 & 0 & 0 \\
\hline 16 & Cf Glomus maculosum Miller \& Walker, 1986. & 0 & 1 & 1 & 0 \\
\hline 17 & Cf Glomus intraradix Schenck \& Smith, 1982. & 1 & 0 & 1 & 1 \\
\hline 18 & Cf Glomus pustulatum Koske, Friese, Walker \& Dalpe, 1986. & 1 & 0 & 0 & 1 \\
\hline 19 & Cf Glomus invermayanum Hall, 1977. & 1 & 1 & 1 & 0 \\
\hline 20 & Cf Glomus claroides Schenck \& Smith, 1982. & 0 & 0 & 1 & 1 \\
\hline 21 & Cf Glomus fulvum Berkeley \& Broome) Trappe \& Gerdermann, 1922. & 1 & 1 & 1 & 0 \\
\hline 22 & Cf Glomus sp. & 1 & 1 & 1 & 0 \\
\hline 23 & Cf Glomus sp. & 0 & 1 & 0 & 1 \\
\hline 24 & Cf Glomus sp. & 1 & 0 & 0 & 1 \\
\hline 25 & Cf Glomus microcarpa (Lqbal \& Bushra, 1980) Morton y Redecker, 2001. & 0 & 1 & 1 & 0 \\
\hline 26 & Cf Gigaspora rosea Nicolson \& Schenck, 1979. & 0 & 0 & 0 & 1 \\
\hline 27 & Cf Glomus fragilistratum Skou \& Jakobsen, 1989. & 0 & 1 & 1 & 0 \\
\hline 28 & Cf Glomus deserticola Trappe, Bloss \& Menge, 1984. & 1 & 0 & 0 & 1 \\
\hline 29 & Cf Glomus formosanum Wu \& Che, 1986. & 1 & 0 & 1 & 1 \\
\hline 30 & Cf Glomus boreale (Traxter) Trappe \& Gerdermann, 1922. & 0 & 1 & 1 & 0 \\
\hline 31 & Cf Glomus fasciculatum Gerd emann \& Trappe, 1974. & 1 & 0 & 0 & 1 \\
\hline & TOTAL & 21 & 16 & 17 & 16 \\
\hline
\end{tabular}

1: presencia de la especie, 0: ausencia de la especie.

ligera, suelos bien drenados, moderadamente profundos, de texturas moderadas a finas, mediana retención de humedad, permeabilidad moderada. Químicamente son suelos de reacción ácida a neutra y fertilidad moderada.

\section{DISCUSIÓN}

Las zonas agroecológicas estudiadas presentaron características edafoclimáticas variadas, las cuales de acuerdo con los resultados de los análisis físico-químicos de suelos de cada zona, reportaron valores de $\mathrm{pH}$ que oscilaron de fuertemente ácidos a moderadamente alcalinos, contenidos de fósforo, materia orgánica y nitrógeno de bajos a medios y valores de calcio, magnesio y potasio en rangos de medios a altos. La rizosfera del suelo en las fincas ganaderas contiene abundantes esporas de HMA en un rango de 1500 a 6000 esporas/ $100 \mathrm{~g}$ de suelo. Los valores densidad de esporas/ 100 $\mathrm{g}$ de suelos encontrados en este estudio, son mayores a las reportadas por Picone (17) quien aisló diversidad y encontró que la densidad de HMA en pasturas que crecen en agroecosistemas de países como Nicaragua y Costa Rica oscilan entre 830 a 2600 esporas/100 g de suelos.

La mayor diversidad de micorrizas arbusculares fue reportada en los suelos de fincas ganaderas pertenecientes a la zona agroecológica 4, en la cual se encuentran dos subclase: la subclase VII sc que posee fincas ganaderas con suelos con pendientes de hasta $12-25 \%$, ligeramente erosionados. Estos suelos están limitados por capas de gravas muy superficiales, $\mathrm{pH}$ fuertemente ácidos, con saturación de bases y contenidos bajos de fósforo y materia orgánica; son pocos profundos y escasa fertilidad. En la subclase VII esc se encuentran fincas con pendientes $1-12 ; 12-25 ; 25-50$ y $50-75 \%$, con erosión moderada a severa. Los suelos son superficiales a profundos, bien drenados, de baja estabilidad estructural, permeabilidad moderada, baja a media retención de humedad, $\mathrm{pH}$ ligeramente ácida a neutra y fertilidad moderada a baja. Presentan limitaciones severas por pendientes fuertemente inclinadas, susceptibles a la erosión y en algunos casos a la baja fertilidad.

En las fincas ganaderas localizadas en la zona 3, se reportaron los menores números de esporas. Esta zona presenta dos subclase de suelos: La subclase VI sc que posee pendientes de $12-$ $25 \%$ y $25-50 \%$; los suelos son superficiales a moderadamente profundos, de textura franca gruesa a arcillosa, excesivamente drenados. Tienen susceptibilidad a la erosión, buena permeabilidad, mediana a baja retención de humedad, $\mathrm{pH}$ neutro a ligeramente ácida y fertilidad moderada. En la subclase VI esc se agrupan suelos con pendientes de $12-25 \%$ 
y 25 - 50\%, con características morfológicas, físicas y químicas muy variadas, la profundidad efectiva varía de superficial a moderada. Presentan textura franco gruesa a franco fina o arcillosa, fertilidad baja a moderada, $\mathrm{pH}$ ácido a neutro, deficiencia de fósforo y macronutrientes y altos contenidos de aluminio; limitando su aptitud a la preservación de la cobertura vegetal. El mantenimiento de pastos naturales exige severas precauciones (sobre pastoreo) a fin de evitar el progreso de la erosión.

El abundante número de esporas $/ 100 \mathrm{~g}$ de suelos encontrados en las condiciones edáficas del agroecosistema de colosuana en el municipio de corozal, probablemente fue debido a la época del muestreo, ya que al momento de la toma de muestra, las diferentes zonas agroecológicas se encontraban en un periodo de sequia prolongada. En estas condiciones las plantas sufren estrés por el déficit de agua, lo que estimula la producción y liberación de metabolitos secundarios por la raíces de las plantas e inducen la esporulación de HMA; el déficit de agua crea una situación adversa que estimula la producción de esporas durante la época seca y conduce a la adaptación y sobrevivencia de los HMA a esa condición (18, 19).

Los HMA se caracterizan por presentar un crecimiento intra e intercelular en la corteza de la raíz y por formar dos tipos de estructuras, arbúsculos y vesículas. Los arbúsculos son hifas que se dividen dicotómicamente, son invaginados por la membrana plasmática de las células corticales y presentan periodos de vida cortos, mientras que las vesículas son estructuras de almacenamiento que se forman en la parte terminal de las hifas. En raíces del pasto colosuana fueron encontradas diversas estructuras colonizantes con mayor predominio de vesículas y menor presencia de arbusculos en la condiciones del experimento. Diferentes patrones de colonización de micorrizas arbusculares como micelios, cordones hifas, vesícula y arbusculos de micorrizas arbusculares han sido observadas en células corticales de raíces en la especie de pasto Bothriochloa pertusa que crecen en condiciones de agroecosistemas calurosos y árido del sureste de la China (20).

El $96.9 \%$ de los aislamiento de HMA correspondieron a especies con características similares género Glomus y $3.1 \%$ al género Gigaspora. Los resultados indicaron que existe baja diversidad de géneros de HMA asociados al pasto colosuana, pero por las características de los morfotipos identificados existe una alta diversidad de especies dentro del género Glomus.
El pastoreo continuo a que son sometidos las fincas ganaderas objeto del presente estudios, crea un ambiente desfavorables que afecta de manera directa la presencia y la diversidad y favorece la tolerancia y adaptación de ciertas especies a estas condiciones $(21,22)$.

La diversidad y el establecimiento de HMA en condiciones de campo están determinados por diversas condiciones tales como: factores físicoquímicas del suelo $(\mathrm{pH}$, contenido de fósforo, temperatura, aireación, textura y contenido de materia orgánica), condiciones climáticas (intensidad y duración de la luz, temperaturas, humedad, épocas de lluvias y épocas secas) y por las prácticas agronómicas (preparación del terreno, aplicación de pesticidas y prácticas culturales). Los suelos disturbados pueden disminuir la densidad de esporas, la longitud del micelio y la riqueza de especie y las condiciones de no labranza estimulan la actividad de las micorrizas (23). Uno de los desafíos que tienen los investigadores en microbiología del suelo, es tratar de establecer el efecto que tiene las condiciones ambientales, edáficas y de manejo de los agroecosistemas de pasturas en la costa Caribe colombiana sobre la diversidad, el establecimiento y la eficiencia de HMA en la productibilidad y sostenibilidad de dichos agroecosistemas.

Los diversos estudios a nivel mundial han demostrados que los HMA, son un recurso biológico alternativo, cuyo manejo y conservación, además de los efectos sobre la productividad vegetal, genera beneficios ambientales al mejorar las condiciones físicoquímicas y biológicas del suelo. Para la implementación de las micorrizas arbusculares como alternativa biológica para el manejo y producción de pasturas en el municipio de Corozal; los ganaderos deben entender que los beneficios de los hongos desde el punto de vista biológico, se debe a la interacción de estos con los diversos grupos de macro y microorganismos presentes alrededor de la raíz del pasto, como aquellos implicados en el ciclado de nutrientes (bacterias fijadoras de nitrógeno y los microorganismos solubilizadores de fosfato). Asimismo, dichos hongos están interactuando con otros microorganismos implicados en el control biológico de hongos y bacterias del suelo que pueden estar causando enfermedades en dicha especie de pasto.

A pesar de existir escasa información sobre diversidad, densidad y porcentaje de colonización de hongos formadores de micorrizas arbusculares asociados a pasto colosuana en Colombia, los resultados obtenidos en el 
presente trabajo en condiciones agroecológicas de las cuatro zonas estudiadas del municipio de Corozal, departamento de Sucre, Colombia; se convierte en uno de las primeras investigaciones que identifica la diversidad, número de esporas y porcentaje de colonización en raíces de micorrizas arbusculares asociada a la rizosfera en esta especie de pasto.

En conclusión, la alta diversidad de morfotipos de HMA asociados a Colosuana se convierte en un recurso biológico alternativo, cuyo manejo, conservación y efectos sobre la productividad, genera beneficios ambientales al mejorar las condiciones físico-químicas y biológicas del suelo. Se propone su inclusión en el inventario de la diversidad de microorganismos en estos agroecosistemas.

\section{Agradecimientos}

A la asociación de ganaderos del departamento de Sucre y al laboratorio de microbiología de la Universidad de Sucre.

\section{REFERENCIAS}

1. Jeffries $P$, Gianinazzi $S$, Perotto $S$, Turnau K, Barea JM. The contribution of arbuscular mycorrhizal fungi in sustainable maintenance of plant health and soil fertility. Biol Fertil Soils 2003; 37(1):1-16

2. Toljander JF, Artursson V, Paul LR, Jansson JK, Finlay RD. Attachment of different soil bacteria to arbuscular mycorrhizal fungal extraradical hyphae is determined by hyphal vitality and fungal species. FEMS Microbiol Lett 2006; 254(1):34-40.

3. Rodríguez $\mathrm{Y}$, Van Tuinen $\mathrm{D}$, Fernández $\mathrm{K}$. Reclasificación taxonómica de dos cepas de hongos micorrízicos arbusculares. Cult Trop 2009; 30(1):31-35.

4. Schübler A, Schwarzitt D, Walker A. New phylam, the Glomeromycota: Phylogeny and evolution. Mycol Res 2001; 105(12):1413-1421.

5. Morton NC, Redecker D. Two new families of Glomales, Archaesporaceae and Paraglomaceae, with two new genera Archaespora and ParaGlomus, based on concordant molecular and morphological characters. Mycologia 2001; 93(1):72-84

6. Walker C, Schüßler A. Nomenclatural clarifications and new taxa in the Glomeromycota. Mycol Res 2004; 108(9):981-982.

7. Sieverding E, Oehl F. Revision of Entrophospora and description of Kuklospora and Intraspora, two new genera in the arbuscular mycorrhizal Glomeromycetes. J Appl Bot Food Qual 2006; 80(1):69-81.
8. Aguilera DM. Documento de trabajo sobre Economía Regional: La Economía del Departamento de Sucre: Ganadería y Sector Público. Cartagena de India: Banco de la República; 2005.

9. Viloria HJ. Documento de trabajo sobre economía regional: La ganadería bovina en las Ilanuras del Caribe Colombiano. Cartagena de Indias: Banco de la República; 2003.

10. Barea J. 2002. Rhizosphere and mycorrhizal of frield crops: Biological resource management connecting. Connecting Science and Policy. Balázs E, Galante E, Lynch JM, Schepers JS, Toutant JP, Werner D, Werry PA Th J, eds. Berlin, Heidelberg, New York: INRA Editions, Springer-Verlag; 2002.

11. Pérez A, Rojas J, Fuentes J. Regresión logística en la evaluación de la esporulación de micorrizas en pasto Bothriochloa pertusa (L) A. Camus. Rev Colombiana Cienc Anim 2009; 1(1):1-18.

12. Pérez CA. Eficiencia de hongos formadores de micorrizas arbusculares (H.M.A.) nativos, asociados a la producción de forraje en la especie de pasto colosuana (Bothriochloa pertusa (L) A. Camus) en el municipio de corozal, departamento de sucre, Colombia. [Tesis Maestría en Microbiología]. Bogotá, Colombia: Universidad de los Andes; 2003.

13. International collection of Arbuscular \& vesicular Arbuscular Mycorrhizal Fungi. (INVAM, by Morton JB., Curator, Good for Basic Research). 2006. URL disponible en: http://invam.caf.wvu.edu/ 
14. Pérez A, Rojas J, Fuentes J. Determinación de un modelo logístico para evaluación in situ de la colonización de micorrizas en pasto Dichanthium aristatum (Benth). Rev Colombiana Cienc Anim 2010; 2(1):73-84.

15. Vertel MM. Comparación entre el análisis canónico de correspondencia y el análisis factorial múltiple en tablas de frecuenciasvariables continúas. [Tesis Maestría]. Bogotá: Universidad de Nacional de Colombia; 2010.

16. R Development Core Team, R: A language and environment for statistical computing, R Vienna, Austria: Foundation for Statistical Computing; 2009. URL Disponible en: http://www.R-project.org

17. Picone $\mathrm{CH}$. Diversity and abundance of arbuscular - mycorrhizal fungus spores in tropical forest and pasture. Biotropica $2000 ; 32(4): 734-750$.

18. Bonilla R, Roucallo B, Garcia B, Jimeno J. Utilización de hongos micorrizógenos en la producción agrícola. Boletín de investigaciones. Valledupar: CORPOICA. 2002.
19. Barrer SE. El uso de hongos micorrízicos arbusculares como una alternativa para la agricultura. Rev Bio Agro 2009; 7(1): 123-133.

20. Tao L, Zhiwei Z. Arbuscular mycorrhizas in a hot and arid ecosystem in southwest China. Appl Soil Ecol 2005; 29(2):135-141.

21. Ahn-Heum E., Gail W, Hartnett D. Effect of ungulate grazer on arbuscular mycorrhizal simbioses and fungal community structure in tall grass prairie. Mycología 2001; 93(2):233-242.

22. Lugo M., Cabello M. Native arbuscular mycorrhizal fungi (AMF) from mountain grassland (Córboba, Argentina), Seasonal variation of fungal spore diversity. Mycologia 2002; 94(4):579-586.

23. Dodd JC. The role of arbuscular mycorrhizal fungi in agro-and natural ecosystems. Outlook on Agriculture 2000; 29(1):55-62. 